\title{
Realigning the Focus of Plagiarism Detection using Plagiarismdetect.com
}

\author{
Elangkeeran A/L Sabapathy \\ Academy of Language Studies, Universiti Teknologi MARA, 23000 Dungun, Malaysia \\ Tel: 60-9-840-0400Ｅmail: keeran@tganu.uitm.edu.my \\ Rozlan Abd Rahim \\ Academy of Language Studies, Universiti Teknologi MARA, 23000 Dungun, Malaysia \\ Tel: 60-9-8400400 E-mail: rozlanab@tganu.uitm.edu.my \\ Kamaruzaman Jusoff (Corresponding author) \\ TropAIR, Faculty of Forestry, Universiti Putra Malaysia, 43400 UPM Serdang, Selangor. Malaysia \\ Tel: 60-3-8946-7176 E-mail: kjusoff@yahoo.com
}

\begin{abstract}
The purpose of this article is to examine the extent to which plagiarismdetect.com, an internet help/tool to detect plagiarism helps academicians tackle the ever-growing problem of plagiarism. Concerned with term papers, essays and most of the time with full-blown research reports, a tool like plagiarismdetect.com may provide an avenue to ease the burden of detecting plagiarism. As far as plagiarism is concerned, not being computer savvy itself can be a bane when faced with students who appear like wizards in the area of managing information from the internet. Tracking down plagiarists is made easy and free by this site and it may still prove to be the nightmare that is needed to check the unprecedented unethical practices within the academic circle as well as curtail plagiarised work from students. Although some people use other people's material as "seed" for generating ideas and to support their own, the point where material ownership becomes plagiarised material is also another area that a detection tool for plagiarism should be able to handle. Other than this, paraphrasing has always been the solution by lecturers for consistent occurrences of students' plagiarised work. How much of paraphrasing can be considered before it borders on plagiarism? Will plagiarismdetect.com be able to live up to its reputation as a tool to detect and to help students and academicians to turn in original pieces of work?
\end{abstract}

Keywords: Plagiarism, Cut and paste, Software, Learning tool, Ethics

\section{Introduction}

The growing interest of institutions in teaching their students academic writing as well as the ability to report findings in an academic manner had inadvertently seen the growth of plagiarism among the writers too. For instance, Chawla (2002) reported that if one copies from one source, it is plagiarism but then if one copies from many sources, it is research. This seems to be the general idea that most people hold when they write an academic paper. However, McKeever (2004) described plagiarism as both a "symptom of declining academic standards" and as providing damning evidence of the "pernicious impact" of internet on society. Reported in negative light as approaching "epidemic" proportions, plagiarism can be considered to be a serious offence and thousands of students are left out in the cold from the paper race annually, being caught using another's material as their own without citing the source. Mounsey (2002:64) points out the institutions of higher learning frown upon plagiarism and students are dealt with mercilessly since the issue reflects the ethics practised at the institution as well.

Although it can be argued that there is little room nowadays for variations in original reporting, the fact remains that students still face the danger of being expelled if caught having similarities in the manner of writing with some other writer they might not even be acquainted with. In line with this thread of argument, it will also be wise to address the fact that with minimum management skills of information from the internet, students using basic "copy and paste" techniques will be able to pull the wool over the supervisor's eyes and pass off at random other peoples' work as their own. The existence of ready-made solutions like "essay-banks" and "paper-mills", further attract and unwittingly make students with money to spend and indulge in plagiarism.

The need to stamp out the problem of plagiarism (Culwin \& Lancaster, 2000) is an old idea but turning an early episode of plagiarism into an awareness creating session as well as a learning zone is essential and a novel one. This opportunity to educate students on the dangers of plagiarism slips by as the academician involved looks at hundreds of academic writing by students within one academic study-term. Time constraints and overwhelming workload in the form of checking students' work at draft stage will allow academicians time to only skim through submitted papers. Other than advising students not to be caught plagiarising, their main concern will be on how to improve the draft papers into 
worthwhile papers. When the papers, after several revisions, reach the academician for evaluation, it is already at its final submission stage, and at this point, there is no turning back if a case of plagiarism is detected.

As such, it will be beneficial for the students to be aware and be actively involved in detecting plagiarism as they prepare the initial paper, go through a number of drafts and finally submit their papers for evaluation. At this stage, it will be well in keeping with the argument, that it is not enough to alert students and warn them about the consequences against plagiarism. Students need to be made more responsible for what they churn out as their writings. Independence and a pride of achievement should entail a student's final piece of writing. When the supervisor of a student's writing spends too much time pointing out content material that need to be shored-up, it is a wonder as to when time is allotted to check if plagiarism exists in the piece. It will be a sad episode indeed when a student is caught for plagiarism after final submission, when the student could have been alerted as to the existence of "plagiarised" material in the piece of writing.

As much as the internet becomes the source of material available for plagiarism due to its exponential growth, it cannot be considered as a boon to writers of academic writings. The far-reaching worldwide web also expedites the detection of plagiarised material. The benefit of doubt should of course be considered when the question of how "original" is original writing and the source from whence the material comes from. Then another aspect is whether the student has acknowledged at all the source of the material. Then too, to what extent has the material been lifted and used as authentic personally generated material. All these questions become questions to be contended with. To ensure early detection of plagiarism and avoidance of being accused at the last possible moment of having used others' material, an on-going methodology needs to be introduced. This will enable students to check at will, when and wherever they wish, the possibility of plagiarism having occurred without their knowledge (assuming that the leeway for original writing has been breached due to no fault of the student). The detecting system should be available at all time, "free" if possible and most importantly economical, incurring minimal cost or none at all.

\section{Issues pertaining to the detection tool}

There was, in short, a need for a plagiarism detecting software that will be easily available and accessible. There were a number of reasons why low-level, rather than sophisticated software was needed at this juncture.

The presence of the plagiarism detecting software like plagiarismdetect.com should be made available to the students from the very beginning of a writing episode. The lecturers' wish to encourage the students to constantly check on their writings to make sure that they do not even mistakenly infringe into the area of copyrights will be a strong enough reason to introduce this software to the students. This availability of the software will create a separate learning zone, impressing upon the students the importance of ethics in writing.

Making available the software to students also helps the students to help themselves to keep giving drafts that do not contain plagiarised material to the supervisor. The supervisor on the other hand will have the peace of mind that they are not overlooking this aspect (plagiarism) of the students' writings. It would have been taken care of from source, i.e. the students would have taken care of it. The empowerment of students to check on their own work also creates a sense of responsibility and pride over the piece of writing they produce for final assessment.

With supervisors and academicians burdened with workload, the "cleaning out" of plagiarised material by students themselves will lessen their burden, as well as that niggling thought that the writing might contain plagiarised material.

The plagiarism detecting software will be easy to use and be user friendly. The academicians rather than the students will appreciate this aspect as most of them are still being introduced and being awed by what the computer and internet is capable of. The students on the other hand will be more adventurous and will find the software quite comfortable to be used. The 'cut and paste' method which is ever popular among students to produce academic pieces of writing will be put to good use by utilising the programme. They will have to copy sections of their work and by running the programme, will be able to look for matches in the web. The feedback given will ensure that students avoid themselves being caught at the most inopportune moment as having submitted plagiarised work.

The most attractive advantage is that this programme is made available free of charge or at a minimal cost to both the academician and the students. plagiarismdetect.com is a free software programme and any payment incurred will only be the payment to have internet access. Unlike some plagiarism detecting software programmes which are available as a money spinning venture, plagiarismdetect.com provides self plagiarism detection without any hidden costs. When the same system is used by the evaluator, students too will have confidence that they are on the right track. Some sophisticated plagiarism detecting software programmes have more accessibility to resources other than that found on the internet (Clough, 2003). This of course is a drawback of the recommended site. However, when students are using the same programme as the lecturer, they will rest assured that they are not going to be pinned down for unintentional plagiarism.

The plagiarism detecting programme recommended actually instils in students the importance of the process involved in writing an academic piece of writing. When the software programme is used judiciously, it can encourage self-access 
learning by the student and reduce the need for cheating (since they know that the lecturer will catch them eventually and it is not the best option for them). plagiarismdetect.com will increase fairness for all students as a more objective and comprehensible manner is used to track students' work, and finally it also works positively for the lecturer as using the programme redirects the burden of proof of plagiarism from the instructor to the software.

Identifying plagiarised work can be time consuming, and a lecturer with a large stack of papers to grade may disqualify a paper as soon as an instance of plagiarism is detected. The software programme approach to detect plagiarism can measure the degree of plagiarism (in percentage), and automatically provide written documentation of the cheating in much less time. When faced with too little time and daunting piles of work to check, the software actually sets the parameter for disqualifying a written piece of work (Niezgoda \& Way, 2005). The lecturer in turn can rest assured that a piece of writing has been disqualified through an objective assessment. The nature of the software programme is such that a thorough analysis can also be carried out of the written work, ensuring comprehensive check rather than an assessment that is marred by suspicion as to the originality of the work.

With the noble idea that a student is in an institution to learn, another benefit of a self-check of plagiarism should be borne in mind as a plagiarism detecting tool is introduced to the students. Coming to terms with the fact that plagiarism can never be completely phased out of academic writings submitted by students for assessment, any techniques that can make a potential plagiarist to read, revise, analyze and synthesize written material, is definitely an improvement over the cat and mouse game that can be played out by the lecturer and the student. Rather than the lecturer and student involved in plagiarism detection trying to outwit each other, a plagiarism detecting software programme may well lead to improved learning. In the process of self-check, the student will try to avoid a report that carries a high percentage of matches to other people's work. So, they will endeavour to revise, rephrase, or paraphrase their writings. As a side-effect of trying to overcome the plagiarism detecting software, perhaps the student who is trying to plagiarize may even wind up inadvertently understanding the subject-matter of the paper quite well.

\section{Prevention versus detection}

While plagiary detection tools like plagiarismdetect.com may be one more tool for keeping in check dishonesty, users of the software programme may be missing the larger issue of academic integrity. Gallant and Drinan (2006) concluded after surveying academic affairs administrators, that "many more institutions have in place the structural and procedural indicators for the policing and punishing of academic dishonesty than those for the promotion and education of academic integrity" (p. 74). Thus, universities using plagiary detection tools should also consider the help that lecturers may provide to educate students about proper writing and citation skills that will improve overall academic integrity on campus. The importance of machine translation and its part in language teaching has always been highlighted by Somers (2001). Plagiarism detecting tools can be considered as machine translation and by creating awareness as to its use, academic writing becomes a much more ethical endeavour.

The methods of fighting plagiarism may generally be divided into two classes according to Lukashenko et al (2007), that is, methods of plagiarism prevention as the first class and methods of plagiarism detection as the second class respectively. If plagiarism is considered by the institution as a social ill, then precautionary and stamping out measures as contemplated in the first class should be adopted. In this manner the fear of being caught will be instilled in students who are submitting their writing pieces for assessment. The knowledge that there is a strong chance of them being caught will overshadow their attempts to plagiarise. Lukashenko et al (2007) believe that this will automatically curtail their attempts to plagiarise. The second class of plagiarism detection however, will encourage a remedial stance; encouraging a cure to the ills of plagiarism. Software tools to detect plagiarism will have a long term effect in creating students who will be careful about infringing areas that may be deemed as plagiary.

A further explanation as to the attributes that determine the application of these two methods by Lukashenko et al (2007), makes it clear that load of work in proportion to the intensity of the method's implementation and the duration of the method's efficiency plays an important part as to the class of fighting plagiarism that need to be adopted. The load of work here refers to the amount of resources including time, energy and finance involved to develop and use the method. Plagiarism prevention can be very time consuming, and to bring it to a fruitful stage will require more time compared to detection of plagiarised work. The duration of efficiency, which translates into the positive effect of the method's realization and maintenance, scores less favourably for plagiarism detection compared to preventive measures. Lukashenko et al (2007) further reiterated that students tend to lose sight of the importance of handing in authentic work over time and may resort to plagiarism. Another aspect that needs to be considered is the perception and intimidation that society imposes upon cases of plagiarism. The prevention method seems to be the preferred method by Lukashenko et al (2007) and this according to them relies heavily on the change of attitude against plagiarism adopted by the academic society.

However, there are ways to ensure that students do not lose sight of the importance of plagiarism. One way will be the submission of academic writings accompanied by the report generated by the detection tool. The report does not only carry the percentage of matches found, it also shows the line for line matches with the number of "hits" each line has. 
The insistence on submitting academic writings with reports generated by the detection tool will ensure that students do not lose sight of the importance of handing in authentic work, and it will be proof enough to show that the students have made attempts to avoid plagiarism. Their intention to avoid plagiarism by showing proof is in itself half the battle won to instil integrity in writing.

The fight against plagiarism is the common goal, whatever the method implemented and to ensure that the method employed is efficient, a combination of both class actions against plagiarism should be adopted. In other words the detection method is applied at the initial stage to achieve a short term result and preventive measures initiated later on to achieve a long term effect. While detection will minimize the act of plagiarism, preventive measures will put in place a permanent safeguard to stamp out these unethical phenomena. Undoubtedly, prevention methods have made significant progress in actively decreasing incidents of plagiarism, and since it is widespread and viewed as a plaguing problem, judiciously implementing detection methods will be a wiser approach to eradicate plagiarism. In fact, detection methods will in time out-mode the prevention methods if detection is given precedence and some effort is undertaken to ensure that students incorporate plagiarism detection as part of their writing process.

\section{The downside to the detection tool}

According to Maurer et. al (2006), commonly in practice there are different plagiarism methods. Some of them include copy - paste plagiarism (copying word to word textual information), paraphrasing (restating same content in different words), translated plagiarism (content translation and use without reference to original work), artistic plagiarism (presenting same work using different media: text, images etc.), idea plagiarism (using similar ideas which are not common knowledge), code plagiarism (using program codes without permission or reference), no proper use of quotation marks (failing to identify exact parts of borrowed content), and misinformation of references (adding reference to incorrect or non existing source).

Since plagiarismdetect.com is a plagiarism detection tool, it is a low level application in all sense. It looks for matches in strings of words and unsophisticated paraphrasing. It immediately traces copy-paste plagiarism without any problems if the source is internet-based. The algorithm also traces poor attempts at paraphrasing. However, if copy/paste is done from sources beyond the internet and corpuses accumulated within the web, then a match will not be traced. As Grover (2003: 3) aptly puts it, "a significant but unquantifiable proportion of the web will never find its way into search engines, and frustratingly, it is precisely the 'invisible' web sources, such as password-protected databases of journal articles and essay banks, which are likely to contain the source of plagiarised content". This puts plagiarismdetect.com at a disadvantage. Furthermore, a qualitative piece of academic writing may also pass off as unplagiarised work if the writer had meticulously veiled the material that is not cited with sophisticated paraphrasing.

Another downside to this plagiarism detecting tool is the inability to trace translated pieces of work. So if someone is to get material from another language and translate it into the English Language, that piece of writing, might as well pass off as unplagiarised material. The same issue also arises with artistic plagiarism. Material derived from other forms of media to disseminate information, if not uploaded onto the internet, will not be traced. Ideas that are not common knowledge will not be detected as plagiarised material if they have not been previously found in the internet. Code plagiarism, misinformation about source of material and the extent to which material has been directly quoted by not placing quotation marks will also be a task beyond plagiarismdetect.com as a plagiarism detection tool.

In cases of intentional plagiarism, the jurisdiction of the person who is grading the paper is sought. When students intentionally plagiarize, it will be found that even the most sophisticated plagiarism detecting tool is quite worthless. Therefore the plagiarism detection tool recommended here should be considered by the institution and academicians, more as a tool to instil in students that integrity in writing is required of them.

\section{Conclusion}

So, if plagiarismdetect.com is not living up to the expectations of being a comprehensive plagiarism detection tool, what may the purpose be to introduce such a tool? The purpose of students coming to Institutions of Higher Education should not be confused as just a paper chase. It should be dealt with much higher integrity. Educating students will be the prime purpose and to this end, putting them through the "mill" so that they will be ready for a job market should not be uppermost in an educator's mind. Although reality may suggest otherwise, the noble thought of creating lifelong learners and the ethics involved in the process of learning should be impressed upon the learners.

By introducing plagiarismdetect.com, the students are first made aware that plagiarism is an issue to contend with. Next, they are taught that plagiarism is frowned upon and therefore need to be avoided when producing their own pieces of writing. The learning process comes in when they critically censure their own product before submitting it for evaluation. Therefore, even a low-level plagiarism detecting tool provided in the form plagiarismdetect.com will empower students to go through the learning process conscientiously. 


\section{References}

Chawla, A. (2002). Devadasis - $\quad$ Sinners or Sinned Against, http://74.125.153.132/search? $q=$ cache:-PNgeVrA2C4J:www.samarthbharat.com/files/devadasihistory.pdf + devadasis\& $c d=3 \& h l=e n \& c t=c \ln k \& g l=m y$. (Accessed: 1 June 2009).

Clough, P. (2003). Old and new challenges in automatic plagiarism detection. Retrieved 1 June 2009 from http://www.jiscpas.ac.uk/site/pubs_detect_paulclough.asp.

Culwin, F. \& Lancaster, T. (2000). A review of electronic services for plagiarism detection in student submissions. LTSN-ICS 1st Annual Conference, Edinburgh, LTSN. Retrieved 1 June 2009 from http://www.ics.ltsn.ac.uk/pub/conf2000/Papers/culwin.htm.

Gallant, T. B. \& Drinan, P. (2006). Institutionalizing Academic Integrity: Administrator Perceptions and Institutional Actions. NASPA Journal, 43(4), pp. 61-81.

Grover, D. (2003). The use of correlation techniques to detect plagiarism. Computer Law and Security Report, 19(1), pp. 36-38.

Lukashenko, R., Graudina, V. \& Grundspenkis, J. (2007). Computer-Based Plagiarism Detection Methods and Tools: An Overview, International Conference on Computer Systems and Technologies (CompSysTech'07- Conference proceedings, 14-15 June 2007), University of Rousse, Bulgaria.

Maurer, H.,Kappe, F. \& Zaka, B. (2006), Plagiarism - A Survey. Journal of Universal Computer Science. 12(8), pp.1050-1084.

McKeever, L. (2004). 'Online plagiarism detection services - saviour or scourge?', Plagiarism: Prevention, Practice \& Policy Conference. (St James Park, Newcastle upon Tyne, 28-30 June 2004. Newcastle) Northumbria University Press, pp. 135-142.

Mounsey, C. (2002). Essays and Dissertations. Oxford: OUP, UK.

Niezgoda, S., \& Way, T.P. (2006). SNITCH: a Software Tool for Detecting Cut and Paste Plagiarism. Proceedings of the. 37th SIGCSE Technical Symposium on Computer Science. Education, March 2006. Houston, Texas, USA. pp. 51-55.

Somers, H. (2001). Three perspectives on MT in the classroom. MT Summit VIII Workshop on Teaching Machine Translation, Santiago de Compostela, pp 25-29. 